\title{
An empirical analysis on influencing factors on organizational silence and its relationship with employee's organizational commitment
}

\author{
Belal Panahi $^{\mathrm{a}}$, SeidMahdi Veiseh ${ }^{\mathrm{b} *}$, Said Divkhar ${ }^{\mathrm{c}}$ and Farideh Kamari ${ }^{\mathrm{d}}$
}

${ }^{a}$ Faculty Member, Department of management, Payame Noor University, PO BOX 19395-3697, Tehran, Iran

${ }^{b}$ Faculty Member of Ilam University, Ilam, Iran

${ }^{c}$ Faculty Member of Islamic Azad University, Iran

${ }^{d}$ Instructor of Ilam education organization and student of M.A in educational technology- Kermanshah Azad University

AR T I C LE I NF O $\quad$ AB S TRACT

Article history:

Received June 25, 2011

Received in Revised form

October, 12, 2011

Accepted 25 December 2011

Available online

7 January 2012

Keywords:

Organizational silence

Attitude

Excellent managers

Supervisor's attitude

Communicational opportunities

Silence behavior

Organizational commitment

\begin{abstract}
Today, there is no doubt that in many organizations, many employees refuse to provide their opinions and comments about the organizational problems. In fact, in many organizations there is a created climate, which often makes employees feel their opinion is not valued. This phenomenon is examined as an organizational silence that by identifying the factors affecting on it we can effectively take steps to eliminate barriers to commenting staff in organizations. In this regard, this paper presents an empirical work conducted on data obtained from 260 employees Payame Noor University of East Azerbaijan Province. These data are analyzed by SPSS software and regression and path analysis tests. The results showed that there is a significant relationship between silence climate dimensions and employee organizational commitment with silence behavior employee. In addition, there is a positive correlation between higher management attitudes and supervisor's attitudes with workers silent behavior. We have also observed that there is a negative correlation between communication opportunities and organizational commitment with employee silence behavior of employees.
\end{abstract}

(C) 2012 Growing Science Ltd. All rights reserved.

\section{Introduction}

Today, organizations expect from the employees to take their responsibilities because competitions, high expectations of the clients and quality-based changes have increased. In the modern world, organizations try to hire people who encounter suitably with difficulties and emphasize on their beliefs. Although this research emphasizes on enabling channels and free relations, most of the employees believe that the organizations do not support their knowledge and relationships. The main barriers on our programs are the lack of trust and organizational silence (Dimitris, \& Vakola, 2007). This research is mainly aimed to investigate the factors, which affect the obligations of the employees and organizational silence.

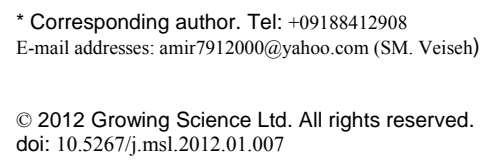




\section{Review of literature}

It is often believed that the employees do not have suitable experience in perceiving main issues. They do not authority over the issues and their behavior can only increase the difficulties and negative attitudes toward the partnership. Increasingly, the managers believe that the employees are encouraged to speak plainly. On the other hand, they use various methods to silence the opposite employees (Dimitris \& Vakola, 2007). There is a direct relationship between the organizational silence and organizational decision-makings but organizational silence generally limits the effectiveness of organizational decision-makings. Organizational silence affects on the development of the organization because it prevents the negative feedbacks by influence of which the organization is not able to examine and correct the errors (Miller, 1972). It is an art to teach the employees how to say "no". These negative behaviors lead to organizational silence, so that the employees neglect them (Cox, 1993). Some people believe that some of the managers work in stressful environments and they cannot change their conditions, which affects on the organizational silence. Therefore, this condition increases the managers' dissatisfaction. The organizations, which accept this trust are regarded as the prosperous organizations (Dimitris \& Vakola, 2007). In general, authors believe that organizational silence is resulted from the followings:

1- Being anxious about the negative feedback,

2- Implicit ideas presented by the managers.

The methods used by the organizations help the managers develop the silence climate. The employees of an organization believe that the problems should not be discussed in such climate. Therefore, the silence climate is appeared under the influence of the employees' activities (Morrison \& Milliken, 2000).

\subsection{The relationship between the top manager's attitude and the employees' silence}

When the super managers believe that the employees are unreliable, they prevent their relationships, explicitly. Discussing the organizational learning, Argyris and Shon (1977) believed that the theories used by the managers are those by which the behavior is shaped. The culture of a group directed by the super manger can present some ideas, which affect on the employees' behavior.

For example, if the group includes the people of who have the same cultures, their behavior is valuable. Therefore, such cultures help the employees improve their job performance (Hofstede, 1980). Moreover, the difference between the cultures causes the employees to keep silent.

The similarity and difference between demographic characteristics such as gender, age, and race of the manager can affect the dispread of ideas associated with the organizational silence. Evidences show that the difference between superiors and subordinates causes the basic distrust (Cox, 1993). Therefore, the demographic difference between the managers and the employees affects on the manager's attitudes toward the employees' ideas (Morrison \& Milliken, 2000). As concluded, the management ideas affect on the managers' and employees' behavior (Mc Gregory, 1960). For example, the managers do not trust the employees when their relationship is not suitable. When the employees find out that the managers have no confidence on them, they seek a way to exit from such system. When an organization is based on the implicit hypothesis (1- the employees are obstinate, 2the managers are the best ones, 3-organizational opposition is undesirable), the managers make some policies in order to prevent any reaction. The followings are the joint structural characteristics of the organizations: 1-Having focus in decision-making 2-The lack of formal feedback mechanisms (Morrison \& Milliken, 2000).

When the managers consider the employees as the opportunist persons, they do not allow them to participate in decision-makings. Although it is necessary to make decisions with the managers who 
believe that the employees are obstinate, the employees prefer to make their behaviors excusable (Sennett, 1998; Forgen, 1999).

For example, when an employee states his/her worry about the suggested changes, the manager considers him/her as a big treat. Therefore, the manager rejects the employee's ideas and ignores undesirable messages delivered by him/her (Morrison \& Milliken, 2000).

\subsection{The relationship between the supervisors' attitude and the employees' silence}

People prefer to interact with those having the same attitude. They also confirm their joint ideas. Therefore, the organizational silence is made when there is no suitable opportunity for the employees to judge about the issues. Since the stability of the employees' position is based on their interactive opportunities, the job affiliation is another variable affecting on the decision-making process and organizational silence. When the employees are obliged to coordinate their activities, they should establish communication with each other. Therefore, they get a chance for sharing their information (Miller, 1972).

When the employees of an organization cannot state their viewpoints, the super manager's attitude affects on their behavior. This issue leads to organizational silence. With regard to this that the supper managers are not disposed toward the negative feedback, the middle - managers can receive the needed information from subordinates. When the manager of a sector reacts against his subordinates, they have no tendency to express their viewpoints about the policies of the organization. Therefore, the organizational silence can be increased (Morrison \& Milliken, 2000).

\subsection{The communicational opportunities and silence of the employees}

When the employees confirm their activities to the groups, they have more opportunities to exchange their information. Therefore, the relationship between them would be improved during decisionmakings. Moreover, their activities are improved under the influence of arranged relations and group work. Organizational silence is caused by some factors including concentrated decision-making, feedback mechanisms, manager's resistance against the employees' arrival and the lack of up-todown feedback. There is a direct relationship between the degree of the employees' relations, social similarity, work force stability and informal networks (Morrison \& Milliken, 2000).

\subsection{The relationship between the employees silence and organizational commitment}

Evidences show that organizational silence leads to the recognition discordance and dissatisfaction of the employees. In addition, the reaction of the managers prevents or delays the negative feedback (Fisher, 1979). In general, the employees of those organizations having rich cultures, experience the feeling of commitment toward the organizational values and objectives. Organizational commitment means the mental affiliation, which includes the loyalty to the organizational values. Organizational commitment is affected by the employees' judgment. When the employees are justly supported, they are eager to participate in decision - makings (Knights et al., 2005)

\section{Research theories and hypothesis}

In this research the variables used by Morrison and Milliken in establishing the climate of silence, are also used in order to present the theoretical model. These variables include the attitude of super manager, the attitude of supervisors and the relational opportunities. Researchers believe that the negative feedback combined with the negative attitude of the managers toward the human nature, financial background and organizational culture affect on the creation of organizational silence ( Dimitris \& Vakola, 2007). 
This research explores the relationship between the aspects of silence climate (including the organizational silence, the attitude of supervisors toward the organizational silence and the communicational opportunities) and the employees' silence. Moreover, the affect of employees' silence on the organizational commitment is also examined.

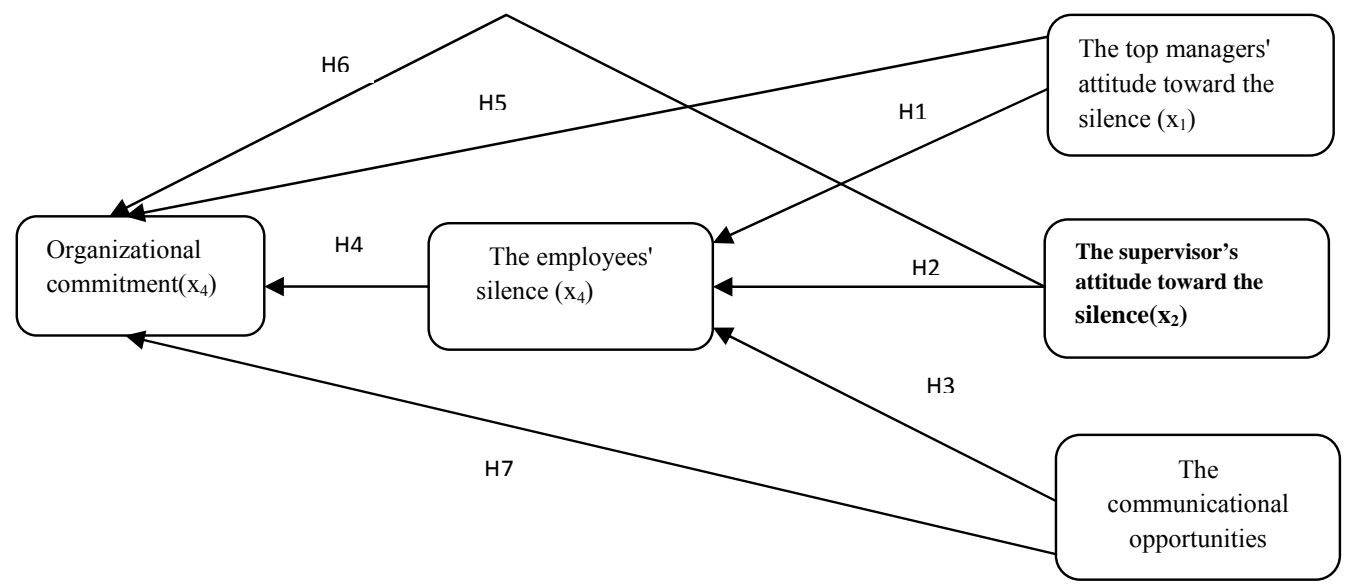

Fig.1. Conceptual model

\section{Research hypothesis}

Hypothesis 1.The top managers' attitude toward the silence behavior affects on the employees silence.

Hypothesis 2: The supervisor's attitude toward the silence behavior affects on the employees' silence.

Hypothesis 3: The communicational opportunities affect on the employees silence.

Hypothesis 4: The employees' silence affects on their organizational commitment.

Hypothesis 5: The top manager's attitude toward the silence affects on the employees organizational commitment.

Hypothesis 6: The supervisor's attitude toward the silence affects on the employees' organizational commitment.

Hypothesis 7: The suitable communicational opportunities affects on the employees' silence.

\section{Researcher population}

In this research, the population includes 260 employees of Payame Noor University in East Azerbaijan. They were selected based on the Cochrane's model.

\section{Instruments and data analysis}

Instruments used in this research included a questionnaire based on the Maria \& Kola's questionnaire and the SPSS software. The questionnaire used in the research included 24 questions. Five out of 24 questions were designed in order to test the attitude of super manager toward the silence and five questions were about the supervisors' attitudes. In addition, in order to examine the employees' silence and organizational commitment, 4 and 5 questions were designed, respectively. The SPSS software was used in order to analyze data. In this regard, the correlation coefficient test was used. It is worth noting that Cronbach's alpha was used in order to examine the reliability of the instruments $(\alpha=0.91)$. 


\section{Data Analysis}

\subsection{Durbin - Watson test}

One of the hypotheses mentioned at regression is related to the errors miscorrelation. When this hypothesis is rejected, it is not possible to use regression. The Durbin - Watson test was used in order to test errors independency. When $\mathrm{n}=1.5-2.5$, Ho is accepted. Therefore, the following hypotheses are suggested:

$\mathrm{H} 0=$ there is no correlation between the errors

$\mathrm{H} 1=$ there is a direct correlation between the errors

\section{Table 1}

D-w test related to the effects of communicational opportunities, the top manager's attitude and the supervisors' attitude on the silence behavior

\begin{tabular}{lllllll} 
Independent variable & $\begin{array}{l}\text { Dependant } \\
\text { variable }\end{array}$ & $\mathrm{R}$ & $\mathrm{R} 2$ & $\begin{array}{l}\text { Adjusted } \\
\text { R2 }\end{array}$ & Std.error & $\begin{array}{l}\text { Durbin } \\
\text { Watson }\end{array}$ \\
\hline $\begin{array}{l}\text { communicational opportunities, } \\
\begin{array}{l}\text { attitude of the top managers and } \\
\text { supervisors }\end{array}\end{array}$ & $\begin{array}{l}\text { Silence } \\
\text { behavior }\end{array}$ & 0.887 & 0.787 & 787 & 0.432 & 1.785 \\
\hline
\end{tabular}

According to the results, $\mathrm{n}=1.78$ and the lack of correlation between the errors is accepted. Therefore, hypothesis 1 is rejected.

\section{Table 2}

$\mathrm{D}-\mathrm{W}$ test related to the affect of communicational opportunities, the top manager's attitude, the supervisors' attitude and the silence behavior on the organizational commitment

\begin{tabular}{lllllll}
\hline Independent variable & $\begin{array}{l}\text { Dependant } \\
\text { variable }\end{array}$ & $\mathrm{R}$ & $\mathrm{R} 2$ & $\begin{array}{l}\text { Adjusted } \\
\text { R2 }\end{array}$ & Std.error & $\begin{array}{l}\text { Durbin- } \\
\text { Watson }\end{array}$ \\
\hline $\begin{array}{l}\text { Communicational opportunities, } \\
\text { attitude of the top managers and } \\
\text { supervisors }\end{array}$ & $\begin{array}{l}\text { Organizational } \\
\text { silence }\end{array}$ & .857 & .735 & .731 & .599 & 1.65 \\
\hline
\end{tabular}

Results show that $n=1.65$. Therefore, miscorrelation between the errors is accepted and H1is rejected.

\section{2. being normality of the errors}

One mentioned hypothesis for using regression test is that the errors should have normal distribution and negative average. In this regard, the standard values of the errors should be accounted and the related histograms should be designed and compared. In this research, the SPSS software is used in order to examine the two histograms. Due to the results, distribution of the errors is normal and there is no problem relative to the use of regression.

\subsection{Multi co linearity test}

Multi co linearity is referred to a condition in which an independent functional variable is separated from other variables. When multi co linearity of a regression equation is high, there is a suitable correlation between the variables. 
Table 3

The results of multi co linearity test

\begin{tabular}{|c|c|c|c|}
\hline Dependent variable & Independent variable & Value & Index \\
\hline \multirow[t]{3}{*}{ Silence behavior } & Attitude of top manager & 0.108 & 5.991 \\
\hline & supervisor's attitude & 0.043 & 14.273 \\
\hline & communicational opportunities & 0.019 & 16.376 \\
\hline Dependent variable & Independent variable & value & Value \\
\hline \multirow{4}{*}{$\begin{array}{l}\text { Organizational } \\
\text { commitment }\end{array}$} & Attitude of top manager & 0.162 & 5.318 \\
\hline & Supervisor's attitude & 0.014 & 14.737 \\
\hline & Communicational opportunities & 0.021 & 12.815 \\
\hline & Silence behavior & 0.113 & 6.101 \\
\hline
\end{tabular}

According to the results, there is no multi co linearity between the independent variables. Therefore, the values related to the independent variables are below 20. Meanwhile, when the index is more than 30 , there is a problem in regression equation.

\section{4 results of regression test related to the hypotheses}

Hypothesis 1: The attitude of top manager toward the silence behavior affects on the employees' silence

\section{Table 4}

The results of regression test related to the attitude of top manager toward the silence behavior of the employees.

\begin{tabular}{lllllllll}
\hline Independent variable & $\begin{array}{l}\text { Dependent } \\
\text { variable }\end{array}$ & $\mathrm{R}$ & $\mathrm{R} 2$ & $\begin{array}{l}\text { Adjusted } \\
\text { R2 }\end{array}$ & $\mathrm{B}$ & Beta & T & Sign \\
\hline Attitude of top manager & Silence behavior & 0.63 & 0.40 & 0.402 & 0.56 & 0.63 & 13.2 & 0.000 \\
\hline
\end{tabular}

As illustrated in table 4, there is a positive correlation between the attitudes of top manager and middle manager toward the employees' silence. Therefore, because $\mathrm{p}=0.000<0.05, \mathrm{H} 1$ is accepted. Moreover, the top manager's attitude towards the employees silence is relatively strong because Beta $=0.635$.

Hypothesis 2: The attitude of the middle manager towards the silence behavior affects on the employees' silence

\section{Table 5}

The results of regression test related to the affect of supervisor's attitude on the employees silence behavior

\begin{tabular}{llllcllll}
\hline Independent variable & $\begin{array}{l}\text { Dependent } \\
\text { variable }\end{array}$ & $\mathrm{R}$ & $\mathrm{R} 2$ & Adjusted R2 & $\mathrm{B}$ & Beta & $\mathrm{T}$ & Sign \\
\hline Supervisor's attitude & $\begin{array}{l}\text { Silence } \\
\text { behavior }\end{array}$ & .846 & .716 & .715 & .733 & .846 & 25.5 & .000 \\
\hline
\end{tabular}

As shown in Table 5, there is a strong correlation between the top managers and supervisor's attitude towards the employees silence behavior. Therefore, because p-value $=0.000<.05, \mathrm{H} 1$ is accepted. Moreover, the attitude of middle manager towards the silence affects on the employees silence behavior because Beta $=0.846$.

Hypothesis 3: The communicational opportunities affects on the employees silence behavior. 
Table 6

The results of regression test related to the effect of communicational opportunities on the employees silence behavior

\begin{tabular}{lllllllll}
\hline $\begin{array}{l}\text { Independent } \\
\text { variable }\end{array}$ & $\begin{array}{l}\text { Dependent } \\
\text { variable }\end{array}$ & $\mathrm{R}$ & $\mathrm{R} 2$ & $\begin{array}{c}\text { Adjusted } \\
\mathrm{R} 2\end{array}$ & $\mathrm{~B}$ & Beta & $\mathrm{T}$ & Sign \\
\hline $\begin{array}{l}\text { Relational } \\
\text { opportunities }\end{array}$ & $\begin{array}{l}\text { Silence } \\
\text { behavior }\end{array}$ & .49 & .24 & .238 & -.31 & -.491 & -9.1 & .000 \\
\hline
\end{tabular}

As seen in Table 6, there is a negative strong correlation between the communicational opportunities and the employees silence behavior. Therefore, because $\mathrm{p}=0.000<0.05, \mathrm{H} 1$ is accepted and because Beta $=-0.491$, the relational opportunities affects on the employees silence behavior.

Hypothesis 4: The employees' silence behavior affects on their organizational commitment.

\section{Table 7}

The results of regression test related to the affect of employees' silence behavior on their organizational commitment

\begin{tabular}{llllcllll}
\hline $\begin{array}{l}\text { Independent } \\
\text { variable }\end{array}$ & $\begin{array}{l}\text { Dependent } \\
\text { variable }\end{array}$ & $\mathrm{R}$ & $\mathrm{R} 2$ & $\begin{array}{c}\text { Adjusted } \\
\mathrm{R} 2\end{array}$ & $\mathrm{~B}$ & Beta & $\mathrm{T}$ & Sign \\
\hline $\begin{array}{l}\text { Organizational } \\
\text { commitment }\end{array}$ & $\begin{array}{l}\text { Silence } \\
\text { behavior }\end{array}$ & .843 & .71 & -.71 & -1.05 & .843 & -25.2 & .000 \\
\hline
\end{tabular}

As illustrated in Table 7, there is a strong correlation between the employees' silence behavior and the organizational commitment. Therefore, because $\mathrm{p}=0.000<0.05, \mathrm{H} 1$ is accepted. Moreover, because Beta $=-0.846$, the employees' silence behavior affects strongly on the organizational commitment.

Hypothesis 5: The attitude of top manager toward the silence affects on the organizational commitment of the employees.

\section{Table 8}

The results of regression test related to the effect of top manager's attitude toward the silence on the organizational commitment of the employees

\begin{tabular}{lllllllll}
\hline Independent variable & Dependent variable & $\mathrm{R}$ & $\mathrm{R} 2$ & Adjusted R2 & $\mathrm{B}$ & Beta & $\mathrm{T}$ & Sign \\
\hline Attitude of the manager & $\begin{array}{l}\text { Organizational } \\
\text { commitment }\end{array}$ & .542 & .29 & .291 & -.59 & -.54 & -10.4 & .000 \\
\hline
\end{tabular}

As shown in Table 8, there is a strongly negative correlation between the attitude of super manager and the employees' organizational commitment.

Hypothesis 6: The attitude of middle managers toward the silence affects on the employees' organizational commitment.

\section{Table 9}

The results of regression test related to the affect of supervisor's attitude toward silence on the organizational commitment

\begin{tabular}{llccccccc}
\hline $\begin{array}{l}\text { Independent } \\
\text { variable }\end{array}$ & $\begin{array}{l}\text { Dependent } \\
\text { variable }\end{array}$ & $\mathrm{R}$ & $\mathrm{R} 2$ & $\begin{array}{c}\text { Adjusted } \\
\mathrm{R} 2\end{array}$ & $\mathrm{~B}$ & Beta & $\mathrm{T}$ & Sign \\
\hline $\begin{array}{l}\text { supervisor's } \\
\text { attitude }\end{array}$ & $\begin{array}{l}\text { Organizational } \\
\text { commitment }\end{array}$ & .679 & .46 & .459 & -.730 & -.679 & -14.9 & .000 \\
\hline
\end{tabular}

Table 9 shows that there is a strong negative relationship between the attitude of supervisors towards the silence and the employees' organizational commitment. Therefore, because $p=0.000<0.05, \mathrm{H} 1$ is 
accepted. Moreover, the attitude of supervisors towards the silence affects on the employees organizational commitment because $\beta=-0.679$.

Hypothesis 7: The suitable communicational opportunities affect on the employees' organizational commitment.

\section{Table 10}

The results of regression test related to the effect of communicational opportunities on the organizational commitment

\begin{tabular}{lllllllll}
\hline Independent variable & Dependent variable & R & R2 & Adjusted R2 & B & Beta & T & Sign \\
\hline $\begin{array}{l}\text { communicational } \\
\text { opportunities }\end{array}$ & $\begin{array}{l}\text { Organizational } \\
\text { commitment }\end{array}$ & 0.54 & 0.29 & 0.292 & 0.424 & 0.543 & 10.38 & .000 \\
\hline
\end{tabular}

As seen in Table 10, there is a strong positive correlation between suitable communicational opportunities and the employees' organizational commitment.

Because $\mathrm{p}=0.000<0.05, \mathrm{H} 1$ is accepted and because Beta $=0.543$, the suitable communicational opportunities affects strongly on the employees' organizational commitment.

\subsection{The results of regression test and path analysis related to the relationship between the variables}

\section{Table 11}

The effects of silence climate on the employees' silence behavior

\begin{tabular}{llcccc}
\hline Regression steps & Input variables & B & Beta & T & Sign \\
\hline Step 1 & Supervisors' attitude & .733 & .846 & 5.514 & .000 \\
\cline { 2 - 6 } Step 2 & Supervisors' attitude & .617 & .713 & 9.327 & .000 \\
& Super managers' attitude & .214 & .242 & 6.572 & .000 \\
\cline { 2 - 7 } Step 3 & Supervisors' attitude & .569 & .658 & 8.409 & .000 \\
& Super managers' attitude & .192 & .218 & 6.257 & .000 \\
& communicational opportunities &. .119 & .189 & 6.054 & .000 \\
\hline $\mathrm{R}^{2}=.787$, Dependent variable $=$ silence behavior & & & & &
\end{tabular}

This regression test includes 3 steps: step 1. The attitude of the supervisors $\left(\mathrm{x}_{1}\right)$

Step 2: The attitude of top managers $\left(\mathrm{x}_{2}\right)$

Step 3: The communicational opportunities $\left(\mathrm{x}_{3}\right)$

Results show that there is a direct correlation between the variables 1 and 2 and dependent variable. Therefore, the structural equation is as the following:

$\mathrm{X}_{4}=1.92+.56 \mathrm{x}_{1}+.192 \mathrm{x}_{2}-.119 \mathrm{x}_{3}$

\section{Table 12}

The results of regression test related to the effect of employees silence on the organizational commitment

\begin{tabular}{llrrrr}
\hline Regression steps & Input variables & B & Beta & T & sign \\
\hline Step 1 & Employees' silence & -1.04 & -.843 & -25.15 & .000 \\
\cline { 2 - 6 } Step 2 & Employees' silence & -.743 & -.759 & -20.50 & .000 \\
& communicational opportunities & .133 & .170 & 4.591 & .000 \\
\hline
\end{tabular}

Dependent variable $=$ organizational commitment $\mathrm{R}^{2}=0.732$

In this test, the first and second variables were silence behavior and communicational opportunities, respectively. Therefore, the structural relationship of the variables is as the following:

$\mathrm{Y}_{1}=8.58-0.743 \mathrm{x}_{4}+0.133 \mathrm{x}_{3}$ 
As we can observe, organizational commitment has negative correlation with silence behavior and positive correlation with communicational opportunities.

\section{Conclusion}

In this paper, we have presented an empirical analysis on influencing factors on organizational silence and its relationship with employee's organizational commitment. The results of this survey show that there was a direct relationship between the aspects of silence climate and the employees' silence behavior. In addition, data analysis showed that there was a direct relationship between the employees' silence behavior and organizational commitment. Therefore, the employees' silence will be increased by the development of silence climate. In other words, the employees' silence is increased when the supervisors' attitude leads to decrease of their communicational opportunities. Regarding the achieved results, the followings are suggested:

- $\quad$ To present a suitable rewarding system for creative ideas,

- To establish the training workshops in order to train the relational skills to the managers and the supervisors,

- To regulate some rules for supporting the employees' attitudes,

- To make decisions about the work groups of the organizations,

- To change the organizational cultures related to the learning organizations and organizational learning,

- $\quad$ To establish some programs in order to improve the human resource management for training skills of decision - making.

In summary, the results of this survey showed that there was a significant relationship between silence climate dimensions and employee organizational commitment with silence behavior employee. In addition, there was a positive correlation between higher management attitudes and supervisor's attitudes with workers silent behavior. We have also observed that there was a negative correlation between communication opportunities and organizational commitment with employee silence behavior of employees.

\section{Acknowledgment}

The authors would like to thank the anonymous referees for constructive comments on earlier version of this work.

\section{References}

Argyris, C. \& Schon, D.A. (1978). Organisational Learning: A Theory of Action Perspective. Addison-Wesley: Reading.

Dickson, W., \& Roethlisberger, F. (1966). Counseling in an Organization: A Sequel to the Hawthorne Researches. Boston, Mass.: Harvard University Press.

Dimitris, B. \& Vakola, M. (2007). Organizational Silence: A new challenge for human resource management. Athens university of economics and business, 1-19.

Fisher, C. (1979). Transmission of positive and negative feedback to subordinates: A laboratory investigation. Journal of Applied Psychology, October, 533-540.

Forgen, J. H. (1999). Why not empowerment? Business and Economic Review, 45(3), 31-33.

Fortado, B. (1994). Informal Supervisory Social Control Strategies. Journal of Management Studies, $31(2), 251-276$.

Henriksen, K., \& Dayton, E. (2006). Organizational Silence and Hidden threats to patient safety. National Council of Chief Clinical Consultants, 5(1), Health Research and Educational Trust.

Hofstede, G. (1980). Culture's consequences: International differences in work-related values. Beverly Hills, CA: Sage. 
Ilgen, D.r., Fisher, C. D., \& Taylor, M.S. (1979). Consequences of individual feedback on behavior in organizations. Journal of Applied Psychology, 64, 349-371.

Knights, J. A., \& Kennedy, B. J. (2005). Psychological Contract Violation: Impacts on Job Satisfaction and Organizational Commitment Among Australian Senior Public Servants. Applied H.R.M. Research, 10(2), 57-72.

McGoman, R.A. (2003). Organizational Discourses: Sounds of Silence, university of western Ontario.

Meyer, G.W. (1994). Social international processing and Social networks: A test of Social influence mechanisms. Human Relation, 47, 1013-1036.

Miller, J. G. (1972). Living systems: The organization. Behavioral Science, 17, 1-82.

Morrison, E., \& Milliken, F. (2000). Organisational Silence: A Barrier to Change and Development in Pluralistic World. Academy of Management Review, 25(4), 706-725.

Organ, D. W. (1988). Organizational Citizenship Behavior: The Good Soldier Syndrome. Lexington, MA: Lexington Books.

Pinder, C. C., \& Harlos, K. P. (2001). Employee silence: quiescence and acquiescence as responses to perceived injustice. In Rowland, K. M. and Ferris, G. R. (Eds), Research in Personnel and Human Resources Management, 20. New York: JAI Press, 331-369.

Rodrigues, A. (2005). The elephant in the room Organizational Silence, www.Sophiaassociates.com.

Sennett, R. (1998). The corrosion of character: the personal learning and interpretation in strategic persistence and reorientation: An empirical exploration. Strategic management Journal, 13, 585608. 